\title{
Advances in development of new tools for the study of phosphohistidine
}

\author{
Mehul V Makwana ${ }^{1,2}$, Richmond Muimo ${ }^{2}$ and Richard FW Jackson ${ }^{1}$
}

Protein phosphorylation is an important post-translational modification that is an integral part of cellular function. The O-phosphorylated amino-acid residues, such as phosphoserine (pSer), phosphothreonine (pThr) and phosphotyrosine (pTyr), have dominated the literature while the acid labile N-linked phosphorylated amino acids, such as phosphohistidine (pHis), have largely been historically overlooked because of the acidic conditions routinely used in amino-acid detection and analysis. This review highlights some misinterpretations that have arisen in the existing literature, pinpoints outstanding questions and potential future directions to clarify the role of pHis in mammalian signalling systems. Particular emphasis is placed on pHis isomerization and the hybrid functionality for both pHis and pTyr of the proposed t-pHis analogue bearing the triazole residue.

Laboratory Investigation advance online publication, 4 December 2017; doi:10.1038/labinvest.2017.126

Protein phosphorylation is one of the most commonly studied post-translational modifications. In general, the phosphorylation of any amino-acid residue results in a change in charge and thus in the protein surface potential. For example, as phosphoryl groups exist mostly as a dianion under physiological conditions, ${ }^{1}$ phosphorylation of the amino acids serine (Ser), threonine (Thr) and tyrosine (Tyr), results in a change from neutral to negative $(-2)$. Hence, it should be of no surprise that phosphorylation affects protein conformation, protein-protein interactions, biochemical pathways and its dysregulation is connected to many disease states. ${ }^{2}$

There are nine known phosphorylated amino-acid residues Ser, Thr, Tyr, histidine (His), lysine (Lys), arginine (Arg), aspartic acid (Asp), glutamic acid (Glu) and cysteine (Cys). ${ }^{2}$ The hydroxy O-linked phospho-residues, phosphoserine (pSer), phosphothreonine (pThr) and phosphotyrosine (pTyr) have been extensively studied, most probably due to their relative stability in acidic conditions routinely used for analysis. Hence, the relatively acid labile N-linked phosphoramidate, carboxy O-linked acyl phosphate and S-linked phosphorothiolate amino-acid residues (His, Lys, Arg; Asp, Glu; Cys, respectively) have been largely overlooked and less frequently reported. Among the phosphoramidates, phosphohistidine (pHis) is very interesting because of its unique chemical properties: first, unlike other phosphorylated residues there are two isomers of pHis; $\tau$ - and $\pi$-pHis, both of which are found in nature (Figure 1). ${ }^{3,4}$ The $\tau$ - and $\pi$-pHis are chemically different from each other in both structure, reactivity and stability under certain conditions (vide infra). Whether the differences in reactivity and stability are mirrored in proteins is not clear at present. Second, pHis serves as a high energy intermediate in the transfer of the phosphoryl group to other amino-acid residues, which is a characteristic not seen with other phosphorylated amino-acid residues. Therefore, not only does pHis change the surface potential of proteins it also possesses transient transferable chemical information that can be potentially tuned depending on the isomer and environment.

His phosphorylation has been found in a number of organisms including bacteria, ${ }^{5}$ fungi ${ }^{6}$ and plants $^{7}$ and its major role is in cell signalling either via two component or multicomponent phosphorelay systems. Cell signalling via a two component phosphorelay has also been found in yeast, ${ }^{6}$ but such processes have not yet been observed in higher eukaryotes (for example, mammals, birds and fish). ${ }^{8}$ The general role of pHis in prokaryotic and lower eukaryotic cells is shown in Figure 2.

Two isoforms of nucleoside diphosphate kinase (NDPK): Nme1/NDPK-A ${ }^{9-13}$ and Nme2/NDPK-B ${ }^{14-19}$ have been

\footnotetext{
${ }^{1}$ Department of Chemistry, University of Sheffield, Sheffield S3 7HF, UK and ${ }^{2}$ Department of Infection, Immunity and Cardiovascular Disease, Medical School, University of Sheffield, Sheffield S10 2RX, UK

Correspondence: Dr R Muimo, PhD, Department of Infection, Immunity and Cardiovascular Disease, Medical School, University of Sheffield, Beech Hill Road, Sheffield S10 2RX, UK or Professor RFW Jackson, PhD, Department of Chemistry, University of Sheffield, Dainton Building, Sheffield S3 7HF, UK

E-mail: r.muimo@sheffield.ac.uk or r.f.w.jackson@sheffield.ac.uk

Received 29 May 2017; revised 27 August 2017; accepted 3 September 2017; published online 4 December 2017
} 
characterized as mammalian His kinases. Other mammalian His kinases exist. Evidence for histone $\mathrm{H} 4$ His kinases (HHKs) activity has been found in regenerating rat liver, ${ }^{20-23}$ foetal rat and human liver, ${ }^{23}$ human hepatocarcinoma tissue, ${ }^{23}$ pancreatic $\beta$ cells, ${ }^{24,25}$ thymus ${ }^{26}$ and Walker-256 carcinosarcomas, ${ }^{20,27}$ but have not been fully characterized or purified. Interestingly, HHKs from regenerating rat liver ${ }^{21}$ and Walker-256-carcinosarcomas ${ }^{27}$ each phosphorylated histone $\mathrm{H} 4$ leading to a $\tau$-pHis residue. In a later study, ${ }^{31} \mathrm{P}$ NMR suggested the presence of $\tau$-pHis on His 18 of phosphorylated histone H4 when Walker-256carcinosarcomas were used as the kinase source. ${ }^{28}$ However, ${ }^{31} \mathrm{P}$ NMR studies suggested the presence of $\pi$-pHis in phosphorylated histone $\mathrm{H} 4$ when using regenerating rat liver as the kinase source. ${ }^{28}$ In this particular case, it is not clear which isomer of pHis is formed and on which His residue. Mammalian pHis phosphatases, which have been characterized include: protein pHis phosphatase 1 (PHPT1); ${ }^{17,29-35}$

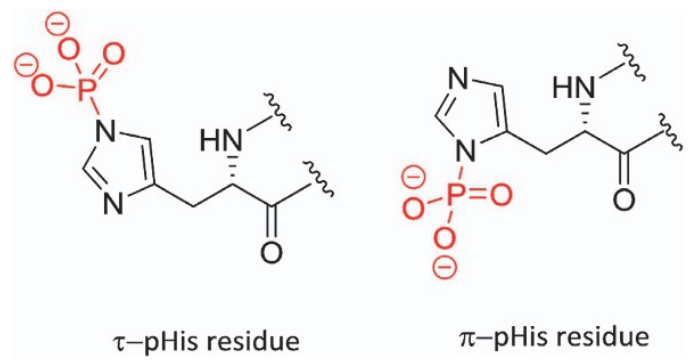

Figure 1 The two isomers of pHis, $\tau$ (tele)- and $\pi($ pros)-pHis residues found in nature existing as dianions under physiological conditions. The $\tau$ isomer is also known $\varepsilon / 3-p H i s$, and the $\pi$ isomer as $\delta / 1$-pHis.
Lys/His phosphatase (LHPPase); ${ }^{36,37}$ Ser Thr protein phosphatases (PP1/2 A/2C); 38,39 T-cell ubiquitin ligand-2 (TULA-2);40,41 and the recently reported phosphoglycerate mutase-5 (PGAM5). ${ }^{42}$ In addition, pHis phosphatase activity has been reported in rat tissue extracts but these have not been fully characterized. ${ }^{43-46}$

Not only is His phosphorylation predicted to be prevalent in eukaryotic proteins, ${ }^{38}$ it has also been associated with important mammalian cellular processes. For example, pHis has been shown to be present in heteromeric G proteins (GNB1), which are involved in G protein signalling, ${ }^{15,47,48}$ KCa3.1 potassium channel, which is involved in ion conductance, ${ }^{18,49}$ ATP-citrate lyase (ACLY), which is involved in cell metabolism, ${ }^{9}$ histone $\mathrm{H} 4$, which is involved in chromatin biology, ${ }^{21,22,28}$ transient receptor potentialvanilloid-5 (TRPV5), which regulates urinary $\mathrm{Ca}^{2+}$ excretion, ${ }^{17}$ and phosphoglycerate mutase 1 (PGAM1), which is involved in glycolysis. ${ }^{50-53}$ Other mammalian pHis proteins include P-selectin, which has an important role in the function of blood platelets, ${ }^{54}$ annexin A1 a multi-functional $\mathrm{Ca}^{2+}$-dependant phospholipid-binding protein found in airway epithelia cells, ${ }^{55}$ thymidylate synthase, which catalyzes $\mathrm{N}$ methylenetetrahydrofolate assisted C(5)-methylation of dUMP required for DNA synthesis, ${ }^{56}$ glucose-6-phosphatase involved in glucose homeostasis, ${ }^{57,58}$ nicotinamide phosphotransferase (NAMTP) involved in reforming nicotinamide adenine dinucleotide $\left(\mathrm{NAD}^{+}\right)$from nicotinamide ${ }^{59}$ and prostatic acid phosphatase, which is found in high levels in prostate cancer cells. ${ }^{60,61}$ However, the functions of many of these pHis proteins, and the specific pHis isomer involved, as well as corresponding kinases and phosphatases remain unknown.

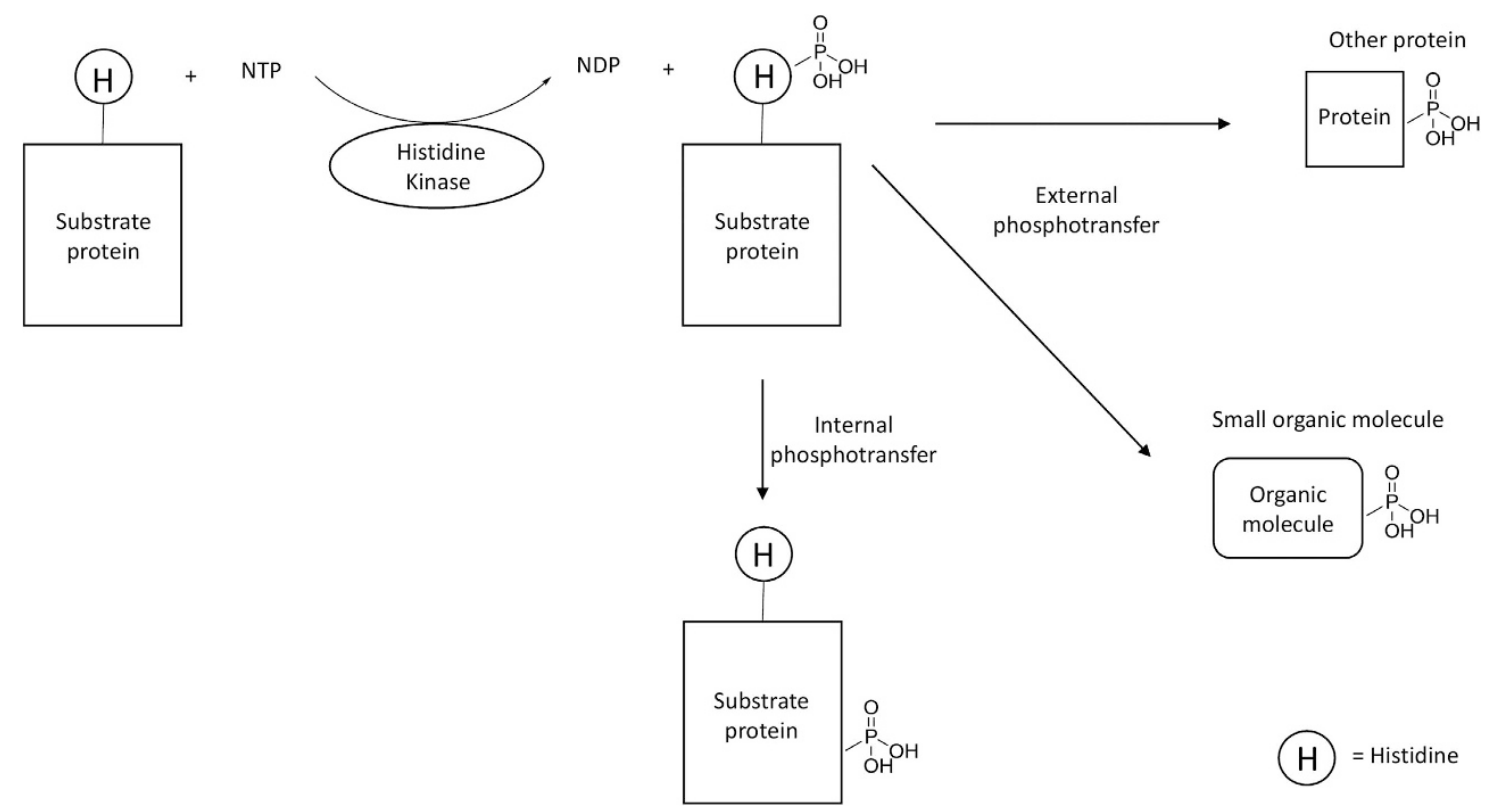

Figure 2 A simplified adopted schematic ${ }^{117}$ showing the general role of pHis known thus far. ${ }^{118}$ 


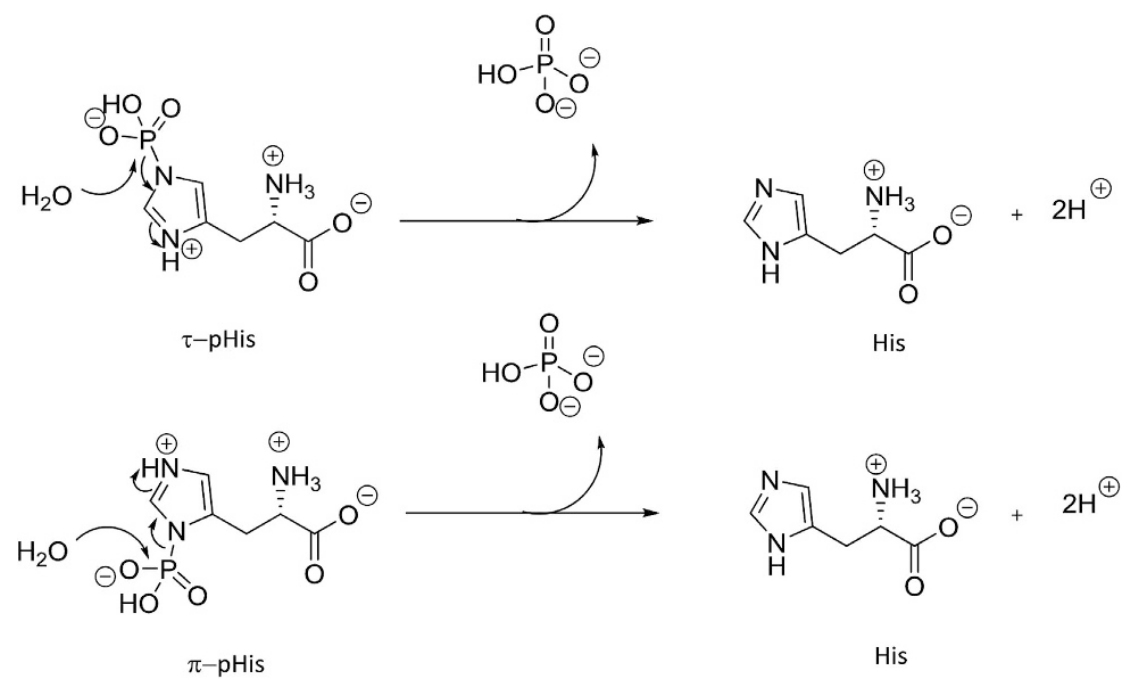

Scheme 1 Hydrolysis of the protonated T - and $\pi$-pHis to His and phosphate.

\section{CHEMISTRY OF PHOSPHOHISTIDINE}

The chemistry of pHis amino acid was first studied by Hultquist et $a l^{62,63}$ and has been covered extensively in a review by Attwood et al. ${ }^{64}$ In summary, pHis residues contain a weak phosphoramidate bond with the phosphoryl group being most susceptible to hydrolysis when the imidazole nitrogen is protonated (Scheme 1). ${ }^{62,63}$ Hence, the rate of hydrolysis of the $\mathrm{pHis}$ is dependent on $\mathrm{pH}$. The respective $\mathrm{pKa}$ values of the imidazole nitrogen suggests hydrolysis can occur even under physiological conditions ( $\mathrm{pKa} 7.3$ for $\pi$ pHis at $46^{\circ} \mathrm{C}^{63}$ and $\mathrm{pKa} 6.4$ for $\tau$-pHis at $\left.25^{\circ} \mathrm{C}^{62}\right)$. It is important to note that $\mathrm{pHis} \mathrm{pKa}$ values have been found to vary depending on salts in solution. Gassner et $a l^{65}$, found $\pi$ and $\tau$-pHis to have a pKas of 7.74 and 6.88, respectively, from the titration of the reaction mixture of His with potassium phosphoramidate adjusted to $\mathrm{pH} 7.2$ at $25^{\circ} \mathrm{C}$.

Hultquist studied the decomposition of $\tau$-pHis over the $\mathrm{pH}$ range $2-5$, by following the decrease in absorbance of $\tau$-pHis, and the decomposition of $\pi$-pHis over the $\mathrm{pH}$ range $2-11$ by following the increase in absorbance of His, each at $46^{\circ} \mathrm{C} .{ }^{63}$ Both isomers decompose more rapidly at low $\mathrm{pH}$ and, at all pHs measured, $\pi$-pHis was less stable than $\tau$-pHis. Unlike $\tau$-pHis, the rate constant for dephosphorylation of $\pi$-pHis decreases smoothly between $\mathrm{pH} 2$ and 4, and remains approximately constant over the $\mathrm{pH}$ range 4-6; above $\mathrm{pH} 6$ $(\sim \mathrm{pKa}$ of imidazole nitrogen of $\pi$-pHis) to $\mathrm{pH} 9$ the rate constant decrease slowly again before a further decrease above $\mathrm{pH} 9$, which is approximately the $\mathrm{pKa}$ of the amine ( 9.6). ${ }^{62-64}$ Nonetheless, the data clearly show both $\pi$-His (pH 9-11, $\left.46^{\circ} \mathrm{C}\right)^{63}$ and $\tau$-pHis $\left(\mathrm{pH} 8-10,80.5^{\circ} \mathrm{C}\right)^{62}$ are stable in solution for extended periods provided the right conditions are used. Hence, application of pHis standards in experiments such as ELISA, chromatography and dot blots with protein conjugates, or any other test where the pHis standard is needed, should be possible.
Within a small neutral peptide (Gly-pHis-Gly) Lecroisey et $a l^{66}$ found the $\pi$-pHis residue to be less stable than the $\tau$-pHis residue in the same position, consistent with Hultquist's findings. Whether the relative stability of $\pi$ - and $\tau$-pHis residues in this case could be explained by $\mathrm{pKa}$ alone is questionable (in the absence of the primary amine) because it is not known to what extent the peptide backbone affects pHis stability. Furthermore, a denatured pHis protein where tertiary interactions are absent may have a half-life that differs from that in the tertiary structure. ${ }^{66,67}$ For example, the enzyme NDPK has a His residue within its active site, which interacts with a nearby Glu residue assisting in the isomer selective phosphorylation to form $\pi$-pHis, but this interaction is absent in the denatured state. ${ }^{68,69}$ Hence, procedures where denaturants are used such as western blots must take this into account. Another important factor to consider in any procedure involving $\mathrm{pHis}$ is the type/concentration of salts present in solution. For example, the calcium salt of $\pi$-pHis was found to be very unstable relative to the sodium salt of $\pi$ pHis. ${ }^{63}$ Thus, each protein phosphorylated on a His residue will likely have a unique half-life under a defined set of conditions and as such, meaningful half-life comparisons can only be made between pHis proteins using normalized conditions.

An important question to be addressed is: does $\pi$-pHis isomerize to $\tau$-pHis or vice versa under any conditions because this will have implications for methods used to study pHis? A good place to start to address the question of isomerization is from the work by Hultquist et al ${ }^{62,63}$, who reported the synthesis, purification and subsequent experimental work on each pHis isomer.

Reaction of His with potassium phosphoramidate in water gives both isomers of pHis, as well as bis-pHis (Scheme 2). The pHis isomers were separated using anion exchange chromatography as either lithium, potassium ${ }^{62}$ or sodium 
<smiles>[NH3+][C@H](Cc1cnc[nH]1)C(=O)[O-]</smiles><smiles>[NH3+][C@@H](Cc1c[nH]cn1)C(=O)[O-]</smiles>

Major tautomer of His in water<smiles>[NH3+][C@@H](Cc1cn(P(=O)([O-])[O-])cn1)C(=O)[O-]</smiles>

$\tau-\mathrm{pHis}$

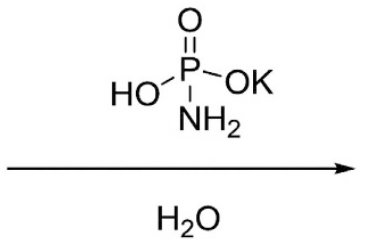<smiles>[NH3+][C@H](Cc1cncn1P(=O)([O-])[O-])C(=O)[O-]</smiles><smiles></smiles>

Bis-pHis

Scheme 2 Synthesis of T-pHis, $\pi$-pHis and bis-pHis by reaction of His with potassium phosphoramidate in water.

salts $^{63}$ after desalting. By following the progress of the reaction by electrophoresis, it was established that $\pi$-pHis formed rapidly before gradually decreasing, accompanied by the formation of $\tau$-pHis and bis-pHis. Similar, observations were made in ${ }^{1} \mathrm{H}$ NMR studies by Gassner et al ${ }^{65}$, where phosphorylation with potassium phosphoramidate $(\mathrm{pH} 7.2$, $25^{\circ} \mathrm{C}$ ) resulted in initial rapid formation of $\pi$-pHis (maximum at $\sim 10 \mathrm{~min}$ ), then bis-pHis (maximum at $\sim 60 \mathrm{~min}$ ), both of which subsequently decomposed, accompanied by a gradual increase in $\tau$-pHis.

The observation of $\pi$-pHis forming more rapidly is consistent with the major tautomer ( $\tau$ protonated nitrogen) of His present in water (Scheme 2) ${ }^{70}$ Hultquist's phosphoryl transfer experiments can be used as a plausible explanation for the accumulation of $\tau$-pHis with the decrease in $\pi$ - and bis-pHis over time (Scheme 3). Phosphoryl transfer reactions (1-8) suggest that the phosphoryl group of pHis can be donated to the imidazole nitrogen of His or $\alpha-\mathrm{N}$-acetyl-His. Comparison of (1) and (5), with (7) and (8) suggests that $\pi$ $\mathrm{pHis}$ has the more labile phosphorus nitrogen $(\mathrm{P}-\mathrm{N})$ bond compared with $\tau$-pHis. Reactions (2) and (4) also show there is a preferential transfer of the $\pi$-phosphoryl group of bispHis to form the $\tau$-pHis. These observations are dependent upon the reaction conditions used $(0.1 \mathrm{M}$ Tris buffer, $\mathrm{pH} 8.5$, at $\left.4{ }^{\circ} \mathrm{C}\right)^{62}$ but provide a credible explanation as to how $\tau$-pHis accumulates over time from the reaction of $\mathrm{His}$ and potassium phosphoramidate.

Importantly, reactions (1), (5) and (7) show that one isomer of pHis can convert to the other isomer, but only via a bimolecular reaction with His. Although this can be viewed as isomerization, it is in fact a bimolecular process and strictly not a unimolecular isomerization as has been proposed to occur under certain conditions, both for $\mathrm{pHis}$ and $\mathrm{pHis}$ residues (Scheme 4). ${ }^{71-75}$ Indeed, Hultquist himself avoided the term isomerization and defined reactions (1), (5) and (7) as conversion of one isomer to the other. ${ }^{63}$ It is unlikely unimolecular isomerization is occurring under acidic conditions because the hydrolysis of $\pi$-pHis $\left(1 \mathrm{M} \mathrm{HCl}, 49^{\circ} \mathrm{C}\right)^{63}$ and $\tau$-pHis $\left(0.5 \mathrm{M} \mathrm{HCl}, 48.5^{\circ} \mathrm{C}\right)^{62}$ followed first-order rate kinetics.

Concerning the question of isomerization of $\mathrm{pHis}$ residues in proteins, Lecroisey et al ${ }^{66}$, found using ${ }^{31} \mathrm{P}$ NMR only the $\pi$-pHis residue in autophosphorylated Dictyostelium NDPK $\left(25^{\circ} \mathrm{C}, 50 \mathrm{mM}\right.$ Tris- $\mathrm{HCl}, 10 \% \mathrm{D}_{2} \mathrm{O}, \mathrm{pH}$ 8.1) and in the denatured state after treatment with $9 \mathrm{M}$ urea (vide supra). Similarly, Williams et $a l^{76}$, observed only $\tau$-pHis by ${ }^{31} \mathrm{P}$ NMR in rat liver ACLY ( $50 \mathrm{mM}$ Tris- $\mathrm{HCl}, 14 \% \mathrm{D}_{2} \mathrm{O}, \mathrm{pH}$ 8.4) both for the functioning enzyme and when denatured with $1 \%$ SDS and $1 \% \beta$-mercaptoethanol. Wagner and $\mathrm{Vu}^{9}$, found that upon base hydrolysis $\left(3 \mathrm{M} \mathrm{KOH}, 120^{\circ} \mathrm{C}, 100 \mathrm{~min}\right)$ of $\left[\gamma^{-32} \mathrm{P}\right]$ 


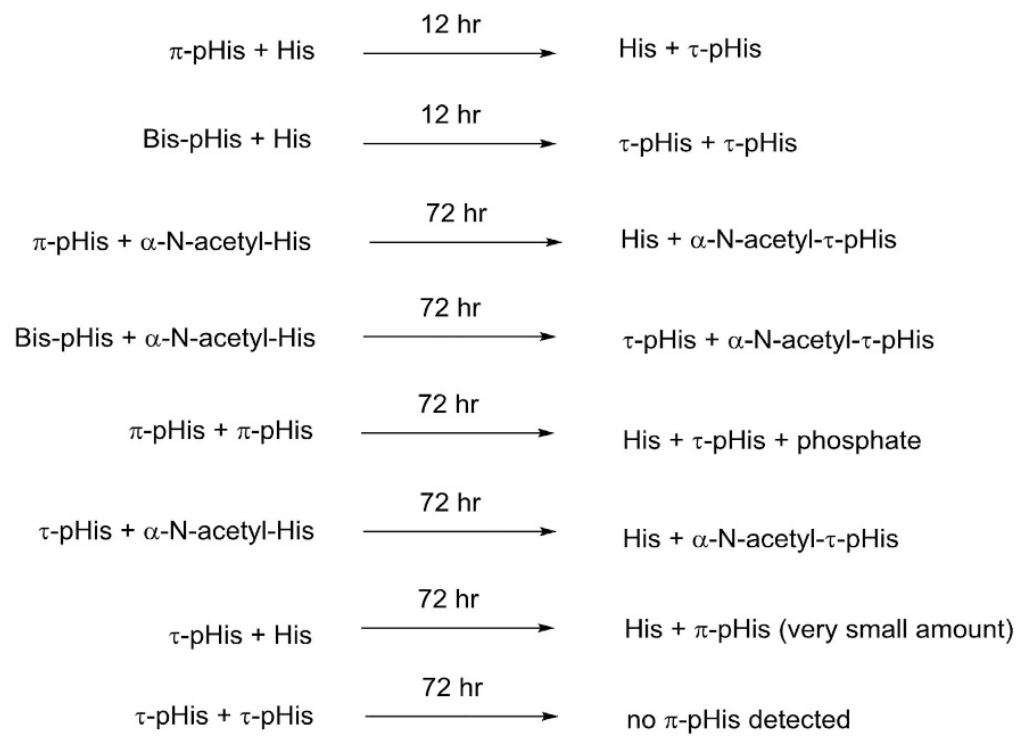

Scheme 3 Phosphoryl transfer reactions of T-pHis, $\pi$-pHis and bis-pHis as donors and His and $\alpha-\mathrm{N}$-acetyl-His as acceptors in $0.1 \mathrm{M}$ Tris buffer, $\mathrm{pH} 8.5$, at $4{ }^{\circ} \mathrm{C} .63$
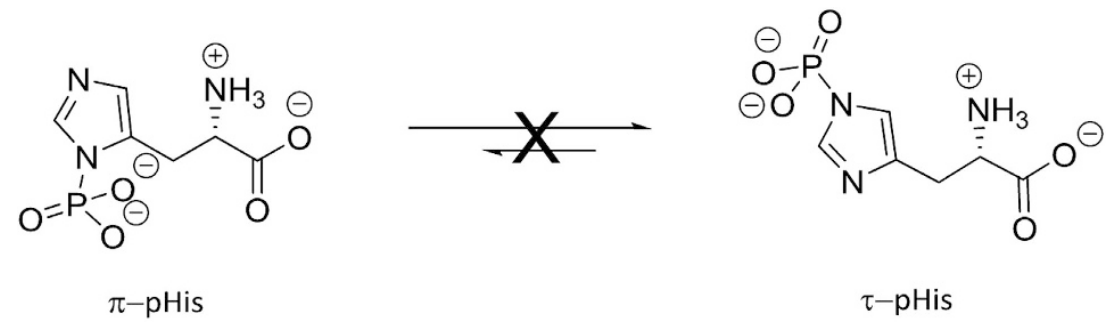

Scheme 4 Inferred unimolecular isomerization of T-pHis to $\pi$-pHis and vice versa that does not occur.

ATP phosphorylated rat liver NDPK, only $\pi$-pHis was detected in the hydrolysate by TLC analysis against the reference compound. In the same study, only $\tau$-pHis was detected by TLC from the base hydrolysate of $\left({ }^{32} \mathrm{P}\right)$ phosphorylated rat adrenal ACLY. ${ }^{9}$ These results show that in these specific examples, isomerization of the $\mathrm{pHis}$ residue does not occur.

By contrast in an early study of phosphorylated human erythrocytic NDPK by Walinder, ${ }^{77}$ phospholysine (pLys) and both isomers of pHis were found in the base hydrolysate after chromatographic separation of the phosphoamino acids. However, ${ }^{31} \mathrm{P}$ NMR, ${ }^{66}$ X-ray crystallography (only the $\pi$ imidazole nitrogen is available for phosphorylation), ${ }^{68,69}$ and base hydrolysate data, ${ }^{9}$ have shown that NDPK is autophosphorylated by ATP on a specific His residue to form the $\pi$ pHis residue exclusively. Similarly, ACLY has been found to be phosphorylated by NDPK or ATP to form $\tau$-pHis only, both by ${ }^{31} \mathrm{P}$ NMR and in the base hydrolysate. ${ }^{9}$ So why the discrepancy with the results from Walinder? It may be that the phosphoryl group of one isomer of pHis was transferred either directly to another His residue giving the other pHis isomer (Scheme 3, eqs. 1 and 7), or to a Lys residue (nitrogen lone pairs are known to accept the phosphoryl group from phosphoramidate containing compounds), ${ }^{79,80}$ which then subsequently phosphorylated His under the particular experimental and analysis conditions used.

Although, in this review, we have focused the topic of pHis isomerization mainly on the ACLY and NDPK, there are other examples of pHis-containing proteins, which have been characterized by ${ }^{31} \mathrm{P} \mathrm{NMR}$, or X-ray crystallography and show no evidence of isomerization. For examples, see: histone $\mathrm{H}_{4}{ }^{28}$ Succinyl-CoA synthase ${ }^{67}$ and phosphocarrier protein HPr. ${ }^{65}$

\section{DETECTION OF PHOSPHOHISTIDINE}

There are many ways to detect $\mathrm{pHis}$ and extensive reviews on the subject exist. ${ }^{71,74,81}$ However, in the context of this review, some of the most important methods need to be discussed briefly. Detection of pHis residues using antibodies will be discussed in a later section. ${ }^{31} \mathrm{P}$ NMR spectroscopy is a useful spectroscopic method to detect $\mathrm{pHis}$ residues but requires large amounts of purified sample. Nonetheless, it is one of the methods that allows pHis isomer distinction against pHis standard chemical shifts. In some cases, the local peptide sequence of the pHis residue is required to generate reference chemical shifts of $\pi$ - and $\tau$-pHis residues within a sequence and this is not always known. For example, Lecroisey et al, ${ }^{66}$ 
found that the ${ }^{31} \mathrm{P}$ NMR chemical shifts of phosphorylated NDPK did not match any known $\tau$-pHis or $\pi$-pHis ${ }^{31} \mathrm{P}$ NMR chemical shifts. The chemical shifts of the pHis residue also differed by a large amount in the native ( -2.72 p.p.m.) and denatured state ( -4.20 p.p.m.) (vide supra for conditions). ${ }^{66}$ However, $\pi$-His phosphorylated peptide (Glu-pHis-Gly, known phosphorylated sequence of NDPK) matched the denatured state chemical shift, which was used as a reference. ${ }^{66}$ Another consideration that must be taken into account when characterizing $\mathrm{pHis}$ by ${ }^{31} \mathrm{P} \mathrm{NMR}$ is $\mathrm{pH}$ because there are three states the phosphoryl group can exist in; as the phosphonic acid, monoanion and dianion, which will effect chemical shifts. ${ }^{65}$ Usually basic conditions $(\mathrm{pH}>8$ ), which stabilize pHis are used, where the phosphoryl groups exists as a dianion. ${ }^{1}$

Wagner and $\mathrm{Vu}^{9}$, approach of detecting either $\pi$ - or $\tau$-pHis from the base hydrolysate of pHis proteins by TLC analysis against pHis standards seems encouraging because of the simplicity of the method. However, Wagner and $\mathrm{Vu}^{9}$ used $\left[\gamma-{ }^{32} \mathrm{P}\right]$ ATP to phosphorylate the protein samples and the TLC was analyzed by autoradiography. On the other hand, detection of $\tau$-pHis in the base hydrolysate of enzymatically phosphorylated histone $\mathrm{H} 4$ using HPLC against pHis standards has been reported and could be used as an alternative. ${ }^{82}$ The method of base hydrolysis, although useful, cannot give any direct information about the site of His phosphorylation or the presence of multiple pHis residues in the protein.

Mass spectrometry (MS) has been used in the detection of phosphorylated amino-acid residues, including phosphorylated His residues. ${ }^{71}$ MS generally uses acidic eluents in chromatographic separation of enzymatically digested peptides before analysis, conditions, which are not suitable for pHis-containing proteins. However, changing the eluent to basic or neutral solution decreases the resolution and sensitivity but mildly acidic conditions $(0.5 \%$ aqueous acetic acid) have proved successful so long as the contact time is kept to a minimum. ${ }^{83}$ Aqueous formic acid $(0.1 \%)$ has also been used. ${ }^{84}$

One of the challenges with MS analysis is how to eliminate false positives when analyzing pHis data. For example, Gonzalez-Sanchez et $a l^{71}$ found phosphorylation of peptide DAPAHDAKD with potassium phosphoramidate resulted in exclusive His phosphorylation, which was confirmed by collision-induced dissociation-tandem MS. The same peptide analyzed by nano-ultraperformance liquid chromatography nano-electrospray ionization MS, eluted with $50 \mathrm{mM}$ ammonium acetate and then loaded under acid conditions ( $\mathrm{pH}$ 2) gave two distinct peaks. One peak was identified as the His phosphorylated peptide (DAPApHDAKD) and the other as the phosphorylated aspartate peptide (DAPAHpDAKD) ${ }^{71}$ The latter experiment demonstrates false positives could be an issue in pHis proteomic MS analysis using certain techniques. Nevertheless, in a recent study Oslund et al ${ }^{84}$ observed a characteristic TRIPLET fingerprint for the decomposition of the pHis residues (neutral losses of 98, 80 and $116 \mathrm{Da}$ ) in collision-induced dissociation MS analysis of various pHis-containing peptides, which could be used to differentiate $\mathrm{pHis}$ from other phosphorylated residues.

All the pHis detection methods described so far require an effective enrichment and purification strategy, as well as a selective phosphorylation method. This can be quite tricky if the protein of interest requires a pHis kinase for phosphorylation because the pHis kinase may be unknown or will also have to be isolated and phosphorylated. Lapek et al ${ }^{85}$, has developed an MS method for the direct analysis of a wholecell lysate, which helps preserve acid labile modifications by using a buffer mixture including ammonium bicarbonate between $\mathrm{pH} 2.5$ and 5 (adjusted with formic acid) in the chromatography before MS analysis. Twenty pHis phosphopeptides were identified but the authors argue that the buffer system limits the analysis to peptide sequences possessing an intrinsic positive charge. Traditional methods avoid this by using more acidic conditions to positively charge the peptide but this is undesirable with acid labile phosphorylated residues.

Despite MS being a powerful tool for the analysis of posttranslational modifications, it cannot give any direct information about the pHis isomer present, which is an important requirement. Thus, the use of a variety of detection methods, which complement each other is needed.

\section{ENRICHMENT OF PHOSPHOHISTIDINE}

The most common ways to enrich a phosphoprotein use an immobilized metal affinity column (IMAC), an immobilized metal oxide columns or an immobilized phospho selective antibody (vide infra). The latter has been more successful because of it being generally more selective for a specific amino-acid residue. ${ }^{86}$ Enrichment of pHis-containing proteins using IMAC has had some success but has its limitations. Muimo et al ${ }^{55}$ enriched His phosphorylated Annexin $\mathrm{Al}$ with $\mathrm{Fe}^{3+}$ and $\mathrm{Ca}^{2+}$ affinity columns, but the method was found to be inefficient. Napper et al ${ }^{87}$ used $\mathrm{Cu}^{2+}$ in what they describe as the selective enrichment of pHiscontaining HPr protein from E. coli. However, this technique is limited to peptides. These two examples suggest IMAC can be used to enrich pHis samples but requires optimization to avoid the acidic conditions typically used to release the bound pHis proteins from the resin, which destroys pHis residues and reduces efficiency.

\section{PHOSPHOHISTIDINE ANALOGUES AND ANTIBODIES}

Antibodies have been used extensively in the detection and enrichment of other phosphorylated residues, namely pTyr, pSer and pThr. ${ }^{86}$ The development of pTyr antibodies in the late $80 \mathrm{~s}$ led to a boom in the research field and this arguably led ultimately to the discovery of protein kinase inhibitor drug Gleevec, which is used to treat leukaemia and other malignancies. ${ }^{88-90}$ Among the detection methods, which have been used to detect phosphorylated amino-acid residues, such 


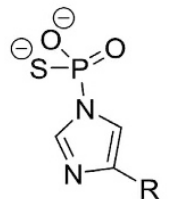

1

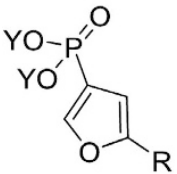

$5=\mathrm{Et}$

$6=\mathrm{H}$

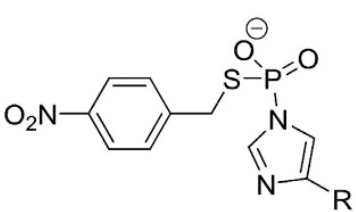

2

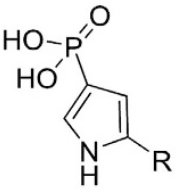

7<smiles>[R]c1cn(C([X])(C(=O)OCC)C(=O)OCC)cn1</smiles>

$3=\mathrm{H}$

$4=F$<smiles>[R]c1cc(P(=O)(O)O)cs1</smiles>

8<smiles>[R]N[C@@H](C[14CH]=[R])C(=O)O[R7]</smiles>

Figure 3 Some of the potential analogues of pHis.

as MS, NMR spectroscopy, radiolabelling $\left({ }^{32} \mathrm{P}\right)$ and dyes, antibodies hold the most potential. Antibodies allow for rapid non-invasive detection (can be used in vivo and in vitro), with high sensitivity (up to femtomolar detection ${ }^{91}$ ) and can be used in enrichment (perhaps most importantly because nearly all the detection methods discussed require a reliable enrichment process before analysis) from whole-cell lysates. ${ }^{92}$ None of the other methods mentioned above has these three characteristics in combination and furthermore antibodies do not have many of the disadvantages associated with other techniques (vide supra) so long as they are selective for a particular antigen or target.

There have not been any reports whereby $\mathrm{pHis}$ has been used successfully to generate selective antibodies, most likely due to its labile nature. Many authors have reported potential pHis analogues (Figure 3) and one of the first approaches was to substitute one of the oxygens of the phosphoryl group for a sulphur atom to give thiophosphorylhistidine $\mathbf{1}$ to give a more stable derivative of pHis. ${ }^{93}$ There are no reports of analogue $\mathbf{1}$ in the generation of pHis antibodies. An antibody was raised against the thiophosphorylhistidine derivative $\mathbf{2}$ but the antibody so raised could not distinguish pHis from other phosphoamino acids. ${ }^{94,95}$ Pirrung et al ${ }^{96}$ reported the preparation of malonate $\mathbf{3}$ and fluoromalonate $\mathbf{4}$ derivatives of His as $\tau$-pHis analogues. However, no biochemical studies using these analogues have been reported. Schenkels et al ${ }^{97}$ reported the synthesis of protected phosphofurylalanine $\mathbf{5}$ while also proposing phosphopyrrole 7 as a potential $\tau$-pHis analogue. Use of the free amino-acid phosphofurylalanine $\mathbf{6}$ allowed the raising of antibodies, but these only detected the antigen, and not natural pHis. ${ }^{98}$ The phosphopyrrole 7 was later synthesized by Attwood et al, ${ }^{64}$ but the polyclonal

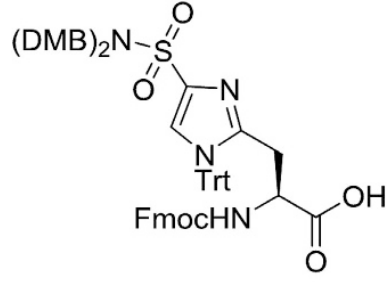

9

Figure 4 Sulphonamide-based transition state analogue of enzymatic pHis dephosphorylation.

antibodies raised against this epitope detected only the analogue and not pHis. Following Schenkels' proposal of phosphofurylalanine $\mathbf{6}$ as a potential pHis analogue, Lilley et a ${ }^{99}$ synthesized phosphothiophene 8 . Polyclonal antibodies generated against this epitope were found to be highly selective for pTyr but did not detect pHis. The results obtained with phosphopyrrole 7 and phosphothiophene 8 suggested that retaining the nitrogen with a lone pair of electrons relative to the phosphoryl group as present in pHis was necessary. In addition, replacement of the labile phosphorus nitrogen bond $(\mathrm{P}-\mathrm{N})$ with a phosphorus carbon (P-C) is probably essential.

Eerland et al ${ }^{100}$ designed and synthesized sulphonamide 9 as a sulphonamide-based transition state analogue of enzymatic pHis dephosphorylation (Figure 4). The analogue was successfully incorporated into peptides, but efforts to use these peptides as pHis phosphatase (PHT) inhibitors, or as baits to pull down pHis-binding proteins, were unfortunately unsuccessful. 101 
<smiles>CCOP(=O)(OCC)c1cn(C[C@H](NC(=O)O)C(=O)O)nn1</smiles>

10<smiles>CCOP(=O)(OCC)c1cnnn1C[C@H](NC(=O)OCc1ccccc1)C(=O)O</smiles>

Boc solid phase peptide synthesis (SPPS)<smiles>[R]C(N)=O</smiles>

11

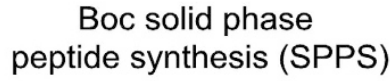

12

Figure 5 Incorporation of proposed t- and $\pi$-pHis analogues $\mathbf{1 0}$ and $\mathbf{1 2}$ in to peptides.<smiles>O=C(O)[C@H](Cn1cc(P(=O)(O)OCc2ccccc2)nn1)NC(F)F</smiles>

13<smiles>O=C(O)[C@H](Cn1nncc1P(=O)(Br)c1ccccc1)NC(F)F</smiles>

14<smiles>NCCn1cc(P(=O)(O)O)nn1</smiles>

15
Figure 6 Fmoc SPPS compatible triazolylalanine $\mathbf{1 3}$ and $\mathbf{1 4} \mathrm{pHis}$ analogues.

Kee et $a^{102}$ synthesized triazole analogues $\mathbf{1 0}$ and $\mathbf{1 2}$ as $\tau$ and $\pi$-pHis analogues, respectively (Figure 5). Density functional theory (DFT) calculations on the residue of triazole analogue 10 suggested a close structural match to $\tau$ pHis but with an observable difference in electrostatic surface potential around the extra nitrogen and lone pair of electrons $^{103}$ (see also Supplementary Figure S1 in reference 102). ${ }^{102}$ Both analogues were incorporated into peptides via Boc solid phase peptide synthesis (SPPS) and peptide 11 was used to generate antibodies after being conjugated to protein KLH (Figure 5). The polyclonal antibodies were found to cross-react with pHis substituted peptide $\mathbf{1 1}$ as assessed by dot blots but not in a peptide sequence independent manner (Rb.\#3 antibodies showed significant cross-reactivity with pTyr containing peptide, see Supplementary Figure S4 in reference 102). ${ }^{102}$

Since this first report, a number of groups have reported the synthesis of these analogues with different protecting groups to allow for incorporation of triazolylalanine $\mathbf{1 0}$ into peptides using Fmoc SPPS. ${ }^{104-106}$ In a 2012 article, McAllister et al, reported the synthesis of Fmoc dibenzyl protected triazolylalanine 13 (Figure 6), which were incorporated into peptides via the Fmoc SPPS strategy. ${ }^{105}$ In a later article, both triazolylalanine analogues $\mathbf{1 3}$ and $\mathbf{1 4}$ were synthesized by Fuhs et $a l,,^{73}$ and incorporated into degenerate peptides again using the Fmoc SPPS strategy (Figures 6 and 8).

Inspired by the earlier work on the generation of pTyr antibodies using the hapten ${ }^{107}$ alone, Kee et al ${ }^{75}$ used the triazolyl ethylamine 15 conjugated to KLH via a linker to give a much simpler epitope for use in immunization (Figure 7). The affinity purified antibodies were used to detect pHis in various known peptides where phosphorylation sites vary widely, including histone $\mathrm{H} 4$, bacterial His kinase, KinB, and the E.Coli metabolic enzyme I (PtsI) and PpSA, illustrating its sequence independence. ${ }^{75}$ However, control experiments to assess the selectivity of the antibody against other phosphorylated amino acids/peptides showed significant cross-reactivity with pTyr as observed by ELISA and dot blots (see Supplementary Figure 3 in reference 75). ${ }^{75}$ These results suggest the triazolyl residue in peptide $\mathbf{1 7}$ has a hybrid functionality for both pHis and pTyr in antibody generation, 
<smiles>[R]C[C@H](NC(=O)C([R])NC(=O)[C@H]([R])NC(=O)C([R])NC(=O)[C@H]([R])NC(=O)[C@H](CS)NC(C)=O)C(=O)NC([R])C(=O)N[C@@H]([R])C(=O)NC([R])C(=O)N[C@@H]([R])C(N)=O</smiles>

$\mathrm{R}=\mathrm{Me}$ or $\mathrm{H}$

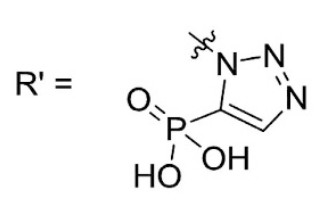

16<smiles>[Y9][Y9]1cc(P(=O)(O)O)nn1</smiles>

17

Figure $\mathbf{8}$ Triazolyl containing peptides $\mathbf{1 6}$ and $\mathbf{1 7}$ used to generate pHis antibodies.

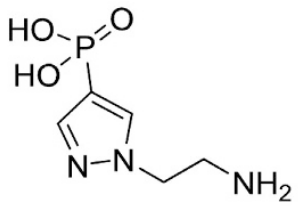

18<smiles>N[C@@H](Cn1cc(P(=O)(O)O)cn1)C(=O)O</smiles>

19
Figure 9 t-pHis pyrazole analogues 18 and 19.

perhaps similar to the azobenzene reported in the 1980 s. ${ }^{108}$ Despite the limitations, Kee et al, study has demonstrated that pHis analogues alone could be effective as epitopes.

Fuhs et $a l^{73}$ took both 13 and 14 and incorporated them in neutral peptides libraries (Figure 8). Immunization with peptides libraries including $\mathbf{1 6}$ and 17 conjugated to KLH generated polyclonal antibodies. The antibodies were tested by dot blots/immunoblots against peptide immunogens 16 and 17, pTyr peptides and two protein targets as standards, His phosphorylated NME1/NME2 and PGAM, which contain a $\pi$-His or a $\tau$-pHis residue, respectively (Figure 8 ). Analysis by immunoblots showed the polyclonal antibodies raised against triazolyl peptides $\mathbf{1 7}$ recognised phosphorylated PGAM, whereas the polyclonal antibody raised against triazolyl peptides $\mathbf{1 6}$ recognised, in a complementary way, phosphorylated NME1. The triazolyalanine $\mathbf{1 2}$ was proposed as a mimic of $\pi$-pHis by Kee et al, ${ }^{102}$ but not used in antibody generation.

Monoclonal antibodies raised with peptides 16 recognised peptides containing residue 16 but not residue 17 on dot blots and vice versa for 17 . The monoclonal antibodies were used in western blots of many mammalian whole-cell lysates and in pHis protein enrichment. ${ }^{73}$ Hunter et al found significant overlap of $\pi$-and $\tau$-pHis proteins binding to all monoclonals in the enrichment data. It is important to point out that in the initial report by Kee et al, ${ }^{102}$ the use of Histone $\mathrm{H} 4$ peptide 11 gave peptide sequence dependent polyclonal antibodies and their later method using triazole ethylamine $\mathbf{1 5}$ gave crossreactive polyclonal antibodies for $\mathrm{pHis}$ and $\mathrm{pTyr}^{75}$

Evaluation of potential interaction between $\mathrm{pHis}$ and $\mathrm{pTyr}$ binding domains indicated that peptides containing unprotected triazole residue in peptide $\mathbf{1 7}$ (as replacement for pTyr) are capable of strongly binding to the prototypical pTyr binding Grb2 SH2 domains. ${ }^{109}$ However, this result apparently contradicted a previous study that showed that $\tau$-pHis could not substitute for pTyr in high-affinity binding of peptides to pTyr binding Grb2 SH2 domains. ${ }^{110}$ It is worth noting that peptides containing a $\mathrm{pHis}$ substitution were not considered in the experimental setup by McAllister et al. As such, it is possible that the Grb2 SH2 binding observed most likely resulted from the ability of triazole residue in peptide $\mathbf{1 7}$ to mimic both pTyr and pHis. Thus, their results are in line with data from antibody generation using the triazole ethylamine 15 (vide supra) and supports the notion that this triazole residue has a hybrid functionality for both $\mathrm{pHis}$ and pTyr. $^{75}$ Furthermore, the peptide sequence dependent antibodies generated to Histone $\mathrm{H} 4$ peptide 11 cross-reacted with pTyr substitution (Rb.\#3 antibodies showed significant crossreactivity with pTyr, see Supplementary Figure S4 in reference 102). ${ }^{102}$ This indicates that peptides containing this triazole residue may not be entirely suitable as tools to raise pHis peptide sequence dependent antibodies.

Owing to the limitations of the triazole residue 17 , Kee et al $^{103}$ reported a second-generation pyrazole ethylamine $\mathbf{1 8}$ as a $\tau$-pHis analogue (Figure 9). DFT calculations by Kee et al show that the pyrazole analogue 18 residue not only closely matches the $\tau$-pHis residue in structure but also electronically. Affinity purified polyclonal antibodies raised to pyrazole analogue 18 conjugated to KLH via a glutaraldehyde linker were found to strongly detect pHis over pTyr, as assessed by ELISA against His phosphorylated BSA and phosphorylated amino-acid conjugates. Concurrently, Lilley et al $^{111}$ reported antibodies raised with the pyrazole aminoacid 19 conjugated to KLH via a glutaraldehyde linker 
(Figure 9). These polyclonal antibodies were also found to have strong selectivity for pHis over pTyr, on dot blots, immunoblots and ELISA against BSA phosphorylated aminoacid conjugates as standards. Polyclonal antibodies reported by Kee et al ${ }^{103}$ were used to detect various in vitro His phosphorylated proteins including PGAM1, mammalian histone $\mathrm{H} 4$ and PtsI, whereas those by Lilley et al ${ }^{111}$ antibodies were used to detect immunoprecipitated protein $\mathrm{G} \beta$ and both NDPK-A/B from HBE cells.

\section{AMINO-ACID SUBSTITUTIONS AS A PHOSPHOMIMETIC}

A useful genetic approach to mimic constitutive phosphorylation of the hydroxy amino acids often involves mutation or substitution of Ser/Thr with Glu or Asp to mimic pSer/pThr or constitutive phosphorylation of these residues. Conversely, substituting Ser or Thr with alanine (Ala) prevents potential phosphorylation and mimics constitutive dephosphorylation. However, Ala is not a perfect mimic for Ser, because of absence of the hydroxy group. The properties of the phosphoryl and carboxy groups (number of oxygen atoms available for bonding, geometry, size and $\mathrm{pKa}$ ) differ and these substitutions do not work successfully in every case, highlighting the differences in the structure of the epitope in these substitutions. Interestingly, pSer/pThr antibodies do not recognize substituted Asp or glutamate (Gln). There is no natural mimic for pTyr. Gln is occasionally reported as a pTyr mimic, but it bears very little chemical similarity to pTyr.

Similarly, there are no natural mimics for His or pHis but several reports exist in the literature involving Ala, phenylalanine (Phe), leucine (Leu) and asparagine (Asn) (possessing hydrophobic, aromatic or polar neutral side chains) substitution of His (a charged side chain). ${ }^{16,112,113}$

Several unnatural pTyr analogues have been developed and incorporated into synthetic peptides by SPPS and, in some cases, this was followed by ligation of the synthetic peptide to recombinant proteins of interest. The pTyr analogues, phosphonomethylphenylalanine (Pmp), and difluorophosphonomethylphenylalanine (F2Pmp), have been invaluable tools in understanding the role of pTyr in cellular processes. Peptides containing pTyr analogues p-carboxymethylphenylalanine have also been used as haptens for generation of selective phosphoantibodies, phosphatase inhibitors, affinity ligands and in structural studies. ${ }^{99}$

Advances in genetic code expansion beyond the naturally encoded amino acids have also enabled site-specific incorporation of pTyr analogues and other unnatural amino acids (UAAs) into proteins to generate proteins with enhanced properties and probes for function. ${ }^{114,115}$ In order to incorporate the UAA at a genetically defined position in a polypeptide chain, the UAA once added to cells is recognized by an orthogonal synthetase/tRNA pair and used to aminoacylate the orthogonal tRNA, which is then decoded by the ribosome in response to a blank codon (inserted into the gene of interest by site-directed mutagenesis at a position of interest) on the mRNA. Thus, for incorporation of pHis analogue, this approach would require development of (a) an aminoacyl-transfer RNA (tRNA) synthetase/tRNA pair that is orthogonal to endogenous synthetases and tRNAs in the host cells; (b) methods to adapt or convert the aminoacyl-tRNA synthetase amino-acid specificity so that it uniquely uses only the pHis analogue and no natural amino acids; (c) a blank codon to direct insertion of the pHis analogue; (d) modification of UAA (pHis analogue) charge to allow increased cellular permeability; and (e) subsequently, a chemo-selective chemical modification reacting only with the incorporated pHis analogue but not the natural amino acids on the protein utilized to modify the UAA. Among several other possibilities and advantages, expression of proteins in which pHis is substituted with a stable pHis analogue will not only help in structural/functional studies but will overcome the complexities associated with identifying the cognate kinases and phosphatases before studying the role of pHis phosphorylation at specific sites. Recently, a method has been developed to produce pure Tyr-phosphorylated proteins by genetic encoding of a stable and neutral pTyr analogue followed by subsequent deprotection. ${ }^{116}$ This approach resulted in site-specific incorporation of native phosphotyrosine into several different proteins including ubiquitin and revealed a potential negative regulatory role of ubiquitin phosphorylation at Tyr59, which exclusively occurs in cancerous tissue but whose significance has hitherto been unknown.

\section{CONCLUSION}

The importance of pHis in mammalian systems continues to be uncovered and suggests pHis function may prove to be much more extensive than presently understood. The data suggest conversion of one isomer of pHis to the other occurs via a bimolecular process under certain conditions but there is no data to support pHis isomerization via a unimolecular process. Therefore, a specific pHis isomer within a protein (which can be thought of as an isolated system) is unlikely to undergo facile conversion to the isomeric pHis. However, caution must be used when handling pHis and pHis proteins because of the labile/ transferable nature of the pHis phosphoryl group under certain conditions.

The half-life of pHis residues in proteins is an important question to be addressed. It is likely that the half-life will depend on the pHis isomer, solutes in solution and protein structure. A hypothetical example could be an exposed pHis residue in the presence of calcium ions where changes in calcium ion concentrations regulate pHis hydrolysis. The presence of $\mathrm{pHis}$ residues, which have long life-times could imply a need for regulatory phosphatases, whereas residues with relatively short life-times may be self-regulating.

It is likely that MS will be used increasingly to detect pHis and the TRIPLET fingerprint approach described by Oslund et $a l^{84}$ will help in pHis peptide analysis. For many other posttranslation modifications if enough is known about the proteins and a pure sample can be obtained, MS analysis 
alone may suffice. However, because of the acid labile nature of pHis and the presence of two isomers other methods of detection in parallel are needed. Methods such as phosphoamino-acid analysis and ${ }^{31} \mathrm{P}$ NMR allow pHis isomers to be distinguished, but require standards.

With the emergence of the long awaited pHis analogues and antibodies, advances are anticipated in the detection and enrichment of existing/unknown pHis proteins and in the understanding of the cellular function of pHis

\section{ACKNOWLEDGMENTS}

We apologize that we were unable, due to space constraints, to include all references to work involving pHis.

\section{DISCLOSURE/CONFLICT OF INTEREST}

The authors declare no conflict of interest.

1. Lad C, Williams NH, Wolfenden R. The rate of hydrolysis of phosphomonoester dianions and the exceptional catalytic proficiencies of protein and inositol phosphatases. Proc Natl Acad Sci USA 2003;100:5607-5610.

2. Hunter T. Why nature chose phosphate to modify proteins. Philos Trans R Soc Lond, Ser B: Biol Sci 2012;367:2513-2516.

3. Zetterqvist $O$. Isolation of $\mathrm{i} 32 \mathrm{p}$ phosphohistidine from rat-liver cell sap after incubation with $32 \mathrm{p}$ adenosine triphosphate. Biochim Biophys Acta 1967;136:279-285.

4. Zetterqvist $\mathrm{O}$. Studies on acid-labile $32 \mathrm{p}$ phosphate in different chromatographic fractions of high-molecular weight material from rat-liver cell sap after incubation with $32 p$ adenosine triphosphate. Biochim Biophys Acta 1967;141:540-546.

5. Khorchid A, Ikura M. Bacterial histidine kinase as signal sensor and transducer. Int J Biochem Cell Biol 2006;38:307-312.

6. Santos JL, Shiozaki K. Fungal histidine kinases. Science's STKE 2001;2001, re1.

7. Perry J, Koteva K, Wright G. Receptor domains of two-component signal transduction systems. Mol Biosyst 2011;7:1388-1398.

8. Besant PG, Attwood PV. Mammalian histidine kinases. Biochim Biophys Acta: Proteins Proteomics 2005;1754:281-290.

9. Wagner PD, Vu ND. Phosphorylation of atp-citrate lyase by nucleoside diphosphate kinase. J Biol Chem 1995;270:21758-21764.

10. Wagner PD, Steeg PS, Vu ND. Two-component kinase-like activity of $\mathrm{nm} 23$ correlates with its motility-suppressing activity. Proc Natl Acad Sci USA 1997;94:9000-9005.

11. Freije JMP, Blay P, MacDonald NJ, et al. Site-directed mutation of nm23-h1 - mutations lacking motility suppressive capacity upon transfection are deficient in histidine-dependent protein phosphotransferase pathways in vitro. J Biol Chem 1997;272:5525-5532.

12. Wagner PD, Vu ND. Histidine to aspartate phosphotransferase activity of $n m 23$ proteins: phosphorylation of aldolase $c$ on asp-319. Biochem J 2000;346:623-630.

13. Hartsough MT, Morrison DK, Salerno M, et al. Nm23-h1 metastasis suppressor phosphorylation of kinase suppressor of ras via a histidine protein kinase pathway. J Biol Chem 2002;277:32389-32399.

14. Klinker JF, Seifert R. Nucleoside diphosphate kinase activity in soluble transducin preparations - biochemical properties and possible role of transducin-beta as phosphorylated enzyme intermediate. Eur J Biochem 1999;261:72-80.

15. Cuello F, Schulze RA, Heemeyer F, et al. Activation of heterotrimeric $g$ proteins by a high energy phosphate transfer via nucleoside diphosphate kinase (ndpk) $\mathrm{b}$ and $\mathrm{g}$ beta subunits - complex formation of ndpk $b$ with $g$ beta gamma dimers and phosphorylation of his-266 in $\mathrm{g}$ beta. J Biol Chem 2003;278: 7220-7226.

16. Hippe HJ, Lutz S, Cuello F, et al. Activation of heterotrimeric g proteins by a high energy phosphate transfer via nucleoside diphosphate kinase (ndpk) $\mathrm{b}$ and $\mathrm{g}$ beta subunits - specific activation of $\mathrm{g}(\mathrm{s})$ alpha by an ndpk b-g beta gamma complex in h10 cells. J Biol Chem 2003;278:7227-7233.
17. Cai X, Srivastava $S$, Surindran $S$, et al. Regulation of the epithelial ca2+ channel trpv 5 by reversible histidine phosphorylation mediated by ndpk-b and phpt1. Mol Biol Cell 2014;25:1244-1250.

18. Srivastava S, Li Z, Ko K, et al. Histidine phosphorylation of the potassium channel kca3.1 by nucleoside diphosphate kinase $\mathrm{b}$ is required for activation of kca3.1 and cd4 t cells. Mol Cell 2006;24: 665-675.

19. Srivastava S, Panda S, Li Z, et al. Histidine phosphorylation relieves copper inhibition in the mammalian potassium channel kca3.1. eLife 2016;5:5.

20. Smith DL, Bruegger BB, Halpern RM, et al. New histone kinases in nuclei of rat tissues. Nature 1973;246:103-104.

21. Chen CC, Smith DL, Bruegger BB, et al. Occurrence and distribution of acid-labile histone phosphates in regenerating rat-liver. Biochemistry 1974;13:3785-3789.

22. Chen $\mathrm{CC}$, Bruegger $\mathrm{BB}$, Kern $\mathrm{CW}$, et al. Phosphorylation of nuclear proteins in rat regenerating liver. Biochemistry 1977;16: 4852-4855.

23. Tan EL, Besant PG, Zu XL, et al. Histone h4 histidine kinase displays the expression pattern of a liver oncodevelopmental marker. Carcinogenesis 2004;25:2083-2088.

24. Kowluru A. Identification and characterization of a novel protein histidine kinase in the islet beta cell: evidence for its regulation by mastoparan, an activator of g-proteins and insulin secretion. Biochem Pharmacol 2002;63:2091-2100.

25. Kowluru A. Defective protein histidine phosphorylation in islets from the goto-kakizaki diabetic rat. Am J Physiol Endocrinol Metabol 2003;285:498-503.

26. Besant PG, Attwood PV. Detection of a mammalian histone h4 kinase that has yeast histidine kinase-like enzymic activity. Int J Biochem Cell Biol 2000;32:243-253.

27. Smith DL, Chen CC, Bruegger BB, et al. Characterization of protein kinases forming acid-labile histone phosphates in walker-256 carcinosarcoma cell-nuclei. Biochemistry 1974;13:3780-3785.

28. Fujitaki JM, Fung G, Oh EY, et al. Characterization of chemical and enzymatic acid-labile phosphorylation of histone h-4 using p-31 nuclear magnetic-resonance. Biochemistry 1981;20:3658-3664.

29. Ek P, Pettersson G, Ek B, et al. Identification and characterization of a mammalian 14-kda phosphohistidine phosphatase. Eur J Biochem 2002;269:5016-5023.

30. Maurer A, Wieland T, Meissl F, et al. The beta-subunit of g proteins is a substrate of protein histidine phosphatase. Biochem Biophys Res Commun 2005;334:1115-1120.

31. Klumpp S, Bechmann G, Maurer A, et al. Atp-citrate lyase as a substrate of protein histidine phosphatase in vertebrates. Biochem Biophys Res Commun 2003;306:110-115.

32. Srivastava $\mathrm{S}$, Zhdanova $\mathrm{O}$, Di L, et al. Protein histidine phosphatase 1 negatively regulates $\mathrm{cd} 4 \mathrm{t}$ cells by inhibiting the $\mathrm{k}(+)$ channel $\mathrm{kca} 3.1$. Proc Natl Acad Sci USA 2008;105:14442-14446.

33. Xu A, Hao J, Zhang Z, et al. 14-kDa phosphohistidine phosphatase and its role in human lung cancer cell migration and invasion. Lung Cancer 2010;67:48-56.

34. Busam RD, Thorsell A-G, Flores A, et al. First structure of a eukaryotic phosphohistidine phosphatase. J Biol Chem 2006;281: 33830-33834.

35. Ma RX, Kanders $E$, Sundh UB, et al. Mutational study of human phosphohistidine phosphatase: effect on enzymatic activity. Biochem Biophys Res Commun 2005;337:887-891.

36. Hiraishi $H$, Yokoi $F$, Kumon A. 3-Phosphohistidine and 6phospholysine are substrates of a 56-kda inorganic pyrophosphatase from bovine liver. Arch Biochem Biophys 1998;349:381-387.

37. Hiraishi $H$, Yokoi $F$, Kumon A. Bovine liver phosphoamidase as a protein histidine/lysine phosphatase. J Biochem 1999;126:368-374.

38. Matthews HR. Protein-kinases and phosphatases that act on histidine, lysine, or arginine residues in eukaryotic proteins - a possible regulator of the mitogen-activated protein-kinase cascade. Pharmacol Ther 1995;67:323-350.

39. Kim YH, Huang JM, Cohen $P$, et al. Protein phosphatases-1, phosphatases-2a, and phosphatases-2c are protein histidine phosphatases. J Biol Chem 1993;268:18513-18518.

40. Back SH, Adapala NS, Barbe MF, et al. Tula-2, a novel histidine phosphatase, regulates bone remodeling by modulating osteoclast function. Cell Mol Life Sci 2013;70:1269-1284. 
41. Thomas DH, Getz TM, Newman TN, et al. A novel histidine tyrosine phosphatase, tula-2, associates with syk and negatively regulates gpvi signaling in platelets. Blood 2010;116:2570-2578.

42. Panda $\mathrm{S}$, Srivastava $\mathrm{S}, \mathrm{Li} \mathrm{Z}$, et al. Identification of PGAM5 as a mammalian protein histidine phosphatase that plays a central role to negatively regulate cd4(+) t cells. Mol Cell 2016;63:457-469.

43. Wong C, Faiola B, Wu W, et al. Phosphohistidine and phospholysine phosphatase-activities in the rat - potential protein-lysine and protein-histidine phosphatases. Biochem J 1993;296:293-296.

44. Ohmori H, Kuba M, Kumon A. 3-Phosphohistidine 6-phospholysine phosphatase from rat-brain as acid-phosphatase. J Biochem 1994;116:380-385.

45. Matthews HR, Mackintosh C. Protein histidine phosphatase-activity in rat-liver and spinach leaves. FEBS Lett 1995;364:51-54.

46. Motojima K, Goto S. Histidyl phosphorylation and dephosphorylation of p36 in rat-liver extract. J Biol Chem 1994;269:9030-9037.

47. Wieland T, Nurnberg B, Ulibarri I, et al. Guanine nucleotide-specific phosphate transfer by guanine-nucleotide-binding regulatory protein beta-subunits - characterization of the phosphorylated amino-acid. J Biol Chem 1993;268:18111-18118.

48. Hippe H-J, Wolf NM, Abu-Taha I, et al. The interaction of nucleoside diphosphate kinase $\mathrm{b}$ with $\mathrm{g}$ beta gamma dimers controls heterotrimeric g protein function. Proc Natl Acad Sci USA 2009;106: 16269-16274.

49. Srivastava S, Choudhury P, Li Z, et al. Phosphatidylinositol 3phosphate indirectly activates kca3.1 via 14 amino acids in the carboxy terminus of kca3.1. Mol Biol Cell 2006;17:146-154.

50. Rose ZB. Evidence for a phosphohistidine protein intermediate in phosphoglycerate mutase reaction. Arch Biochem Biophys 1970;140: 508-513.

51. Han CH, Rose ZB. Active-site phosphohistidine peptides from red-cell bisphosphoglycerate synthease and yeast phosphoglycerate mutase. J Biol Chem 1979;254:8836-8840.

52. Rose ZB. The enzymology of 2,3-bisphosphoglycerate. Adv Enzymol Relat Areas Mol Biol 1980;51:211-253.

53. Heiden MGV, Locasale JW, Swanson KD, et al. Evidence for an alternative glycolytic pathway in rapidly proliferating cells. Science 2010;329:1492-1499.

54. Crovello CS, Furie BC, Furie B. Histidine phosphorylation of p-selectin upon stimulation of human platelets - a novel pathway for activationdependent signal-transduction. Cell 1995;82:279-286.

55. Muimo R, Hornickova Z, Riemen CE, et al. Histidine phosphorylation of annexin $\mathrm{i}$ in airway epithelia. J Biol Chem 2000;275:36632-36636.

56. Fraczyk $T$, Ruman $T$, Rut $D$, et al. Histidine phosphorylation, or tyrosine nitration, affect thymidylate synthase properties. Pteridines 2009;20: 137-142.

57. Ghosh A, Shieh JJ, Pan CJ, et al. The catalytic center of glucose-6phosphatase - his176 is the nucleophile forming the phosphohistidine-enzyme intermediate during catalysis. J Biol Chem 2002;277:32837-32842.

58. Ghosh A, Shieh JJ, Pan CJ, et al. Histidine 167 is the phosphate acceptor in glucose-6-phosphatase-beta forming a phosphohistidine enzyme intermediate during catalysis. J Biol Chem 2004;279:12479-12483.

59. Burgos ES, Ho M-C, Almo SC, et al. A phosphoenzyme mimic, overlapping catalytic sites and reaction coordinate motion for human nampt. Proc Natl Acad Sci USA 2009;106:13748-13753.

60. Ostrowski W. Isolation of tau-phosphohistidine from a phosphorylenzyme intermediate of human prostatic acid-phosphatase. Biochim Biophys Acta 1978;526:147-153.

61. Muniyan S, Chaturvedi NK, Dwyer JG, et al. Human prostatic acid phosphatase: structure, function and regulation. Int J Mol Sci 2013;14: 10438-10464.

62. Hultquist DE, Moyer RW, Boyer PD. The preparation and characterization of 1-phosphohistidine and 3-phosphohistidine. Biochemistry 1966;5:322-331.

63. Hultquist DE. Preparation and characterization of phosphorylated derivatives of histidine. Biochim Biophys Acta 1968;153:329-340.

64. Attwood PV, Piggott MJ, Zu XL, et al. Focus on phosphohistidine. Amino Acids 2007;32:145-156.

65. Gassner M, Stehlik D, Schrecker O, et al. Phosphoenolpyruvatedependent phosphotransferase system of staphylococcus-aureus.2. $\mathrm{H}-1$ and $\mathrm{p}-31 \mathrm{nmr}$-studies on phosphocarrier protein-hpr, phosphohistidines and phosphorylated-hpr. Eur J Biochem 1977;75:287-296.
66. Lecroisey A, Lascu I, Bominaar A, et al. Phosphorylation mechanism of nucleoside diphosphate kinase - p-31-nuclear magnetic-resonance studies. Biochemistry 1995:34:12445-12450.

67. Wolodko WT, Fraser ME, James MNG, et al. The crystal-structure of succinyl-coa synthetase from escherichia-coli at 2.5-angstrom resolution. J Biol Chem 1994;269:10883-10890.

68. Cherfils J, Morera S, Lascu I, et al. X-ray structure of nucleoside diphosphate kinase complexed with thymidine diphosphate and mg2+ at 2-angstrom resolution. Biochemistry 1994;33:9062-9069.

69. Morera S, Lascu I, Dumas C, et al. Adenosine 5'-diphosphate binding and the active-site of nucleoside diphosphate kinase. Biochemistry 1994;33:459-467.

70. Roberts JD, Yu C, Flanagan C, et al. A n-15 nuclear magneticresonance study of the acid-base and tautomeric equilibria of 4substituted imidazoles and its relevance to the catalytic mechanism of alpha-lytic protease. J Am Chem Soc 1982;104:3945-3949.

71. Gonzalez-Sanchez M-B, Lanucara F, Helm M, et al. Attempting to rewrite history: challenges with the analysis of histidinephosphorylated peptides. Biochem Soc Trans 2013:41:1089-1095.

72. Fuhs SR, Hunter T. Phisphorylation: the emergence of histidine phosphorylation as a reversible regulatory modification. Curr Opin Cell Biol 2017;45:8-16.

73. Fuhs SR, Meisenhelder J, Aslanian A, et al. Monoclonal 1- and 3phosphohistidine antibodies: new tools to study histidine phosphorylation. Cell 2015;162:198-210.

74. Kee J-M, Muir TW. Chasing phosphohistidine, an elusive sibling in the phosphoamino acid family. ACS Chem Biol 2012;7:44-51.

75. Kee JM, Oslund RC, Perlman DH, et al. A pan-specific antibody for direct detection of protein histidine phosphorylation. Nat Chem Biol 2013;9:416-421.

76. Williams SP, Sykes BD, Bridger WA. P-31 nuclear magnetic-resonance study of the active-site phosphohistidine and regulatory phosphoserine residues of rat-liver atp-citrate lyase. Biochemistry 1985;24: 5527-5531.

77. Walinder $\mathrm{O}$. Identification of a phosphate-incorporating protein from bovine liver as nucleoside diphosphate kinase and isolation of $1-32 p-$ phosphohistidine 3-32p-phosphohistidine and n-epsilon-32-p-phospholysine from erythrocytic nucleoside diphosphate kinase incubated with adenosine triphosphate-32p. J Biol Chem 1968;243: 3947-3952.

78. Mardh $\mathrm{S}$, Ljungstr $\mathrm{O}$, Hogstedt $\mathrm{S}$, et al. Studies on a rat-liver cell-sap protein yielding 3- $p$-32 -phosphohistidine after incubation with $p-32$ atp and alkaline hydrolysis - identification of protein as atp citrate lyase. Biochim Biophys Acta 1971;251:419-426.

79. Jencks WP, Gilchris M. Reactions of nucleophilic reagents with phosphoramidate. J Am Chem Soc 1965;87:3199-3209.

80. Duclos B, Marcandier S, Cozzone AJ. Chemical-properties and separation of phosphoamino acids by thin-layer chromatography and or electrophoresis. Methods Enzymol 1991;201:10-21.

81. Besant PG, Attwood PV. Detection and analysis of protein histidine phosphorylation. Mol Cell Biochem 2009;329:93-106.

82. Huebner VD, Matthews HR. Phosphorylation of histidine in proteins by a nuclear extract of physarum-polycephalum plasmodia. J Biol Chem 1985;260:6106-6113.

83. Kleinnijenhuis AJ, Kjeldsen F, Kallipolitis B, et al. Analysis of histidine phosphorylation using tandem $\mathrm{ms}$ and ion - electron reactions. Anal Chem 2007;79:7450-7456.

84. Oslund RC, Kee J-M, Couvillon AD, et al. A phosphohistidine proteomics strategy based on elucidation of a unique gas-phase phosphopeptide fragmentation mechanism. J Am Chem Soc 2014;136:12899-12911.

85. Lapek Jr. JD , Tombline G, Kellersberger KA, et al. Evidence of histidine and aspartic acid phosphorylation in human prostate cancer cells. Naunyn-Schmiedeberg's Arch Pharmacol 2015;388:161-173.

86. Reinders J, Sickmann A. State-of-the-art in phosphoproteomics. Proteomics 2005;5:4052-4061.

87. Napper S, Kindrachuk J, Olson DJH, et al. Selective extraction and characterization of a histidine-phosphorylated peptide using immobilized copper(ii) ion affinity chromatography and matrix-assisted laser desorption/ionization time-of-flight mass spectrometry. Anal Chem 2003;75:1741-1747.

88. Druker BJ. Molecularly targeted therapy: have the floodgates opened? Oncologist 2004;9:357-360. 
89. Cohen P. Protein kinases - the major drug targets of the twenty-first century? Nat Rev Drug Discov 2002;1:309-315.

90. Hunter T. Tyrosine phosphorylation: thirty years and counting. Curr Opin Cell Biol 2009;21:140-146.

91. Kaufmann $H$, Bailey $J E$, Fussenegger $M$. Use of antibodies for detection of phosphorylated proteins separated by twodimensional gel electrophoresis. Proteomics 2001;1:194-199.

92. Pandey A, Podtelejnikov AV, Blagoev B, et al. Analysis of receptor signaling pathways by mass spectrometry: identification of vav- 2 as a substrate of the epidermal and platelet-derived growth factor receptors. Proc Natl Acad Sci USA 2000;97:179-184.

93. Lasker $M$, Bui $C D$, Besant $P G$, et al. Protein histidine phosphorylation: increased stability of thiophosphohistidine. Protein Sci 1999;8: 2177-2185.

94. Allen JJ, Li M, Brinkworth CS, et al. A semisynthetic epitope for kinase substrates. Nat Methods 2007;4:511-516.

95. Carlson HK, Plate L, Price MS, et al. Use of a semisynthetic epitope to probe histidine kinase activity and regulation. Anal Biochem 2010;397:139-143.

96. Pirrung MC, Pei T, Drabik SJ, et al. Preparation and incorporation into small peptides of phosphohistidine analogs: study of prokaryotic two-component signal transduction systems. Abstr Pap Am Chem S 1999;218U139-U.

97. Schenkels C, Erni B, Reymond JL. Phosphofurylalanine, a stable analog of phosphohistidine. Bioorg Med Chem Lett 1999;9:1443-1446.

98. Schenkels C, Chemistry and biology of phosphohistidines analogs: University of Bern, 2001.

99. Lilley M, Mambwe B, Jackson RFW, et al. 4-Phosphothiophen-2-yl alanine: a new 5-membered analogue of phosphotyrosine. Chem Commun 2014;50:9343-9345.

100. Eerland MF, Hedberg C. Design and synthesis of an fmoc-sppscompatible amino acid building block mimicking the transition state of phosphohistidine phosphatase. J Org Chem 2012;77:2047-2052.

101. Eerland $M$, Design, synthesis and evaluation of php inhibitors: Technical University of Dortmund, 2015.

102. Kee J-M, Villani B, Carpenter LR, et al. Development of stable phosphohistidine analogues. J Am Chem Soc 2010;132:14327-14329.

103. Kee J-M, Oslund RC, Couvillon $A D$, et al. A second-generation phosphohistidine analog for production of phosphohistidine antibodies. Org Lett 2015;17:187-189.

104. McAllister TE, Nix MG, Webb ME. Fmoc-chemistry of a stable phosphohistidine analogue. Chem Commun 2011;47:1297-1299.
105. McAllister TE, Webb ME. Triazole phosphohistidine analogues compatible with the fmoc-strategy. Org Biomol Chem 2012;10:4043-4049.

106. Mukai S, Flematti GR, Byrne LT, et al. Stable triazolylphosphonate analogues of phosphohistidine. Amino Acids 2012;43:857-874.

107. Frackelton AR, Posner M, Kannan B, et al. Generation of monoclonalantibodies against phosphotyrosine and their use for affinity purification of phosphotyrosine-containing proteins. Methods Enzymol 1991;201:79-92.

108. Frackelton AR, Ross AH, Eisen HN. Characterization and use of monoclonal-antibodies for isolation of phosphotyrosyl proteins from retrovirus-transformed cells and growth factor-stimulated cells. Mol Cell Biol 1983;3:1343-1352.

109. McAllister TE, Horner KA, Webb ME. Evaluation of the interaction between phosphohistidine analogues and phosphotyrosine binding domains. Chem Bio Chem 2014;15:1088-1091.

110. Senderowicz L, Wang JX, Wang LY, et al. 3-Phosphohistidine cannot replace phosphotyrosine in high-affinity binding to phosphotyrosine binding or src homology 2 domains. Biochemistry 1997;36: 10538-10544.

111. Lilley M, Mambwe B, Thompson MJ, et al. 4-Phosphopyrazol-2-yl alanine: a non-hydrolysable analogue of phosphohistidine. Chem Commun 2015;51:7305-7308.

112. Hippe HJ, Luedde $M$, Lutz $S$, et al. Regulation of cardiac camp synthesis and contractility by nucleoside diphosphate kinase b/g protein beta gamma dimer complexes. Circul Res 2007;100: 1191-1199.

113. King Jr. JD, Lee J, Riemen CE, et al. Role of binding and nucleoside diphosphate kinase $a$ in the regulation of the cystic fibrosis transmembrane conductance regulator by amp-activated protein kinase. J Biol Chem 2012;287:33389-33400.

114. Xie J, Supekova L, Schultz PGA genetically encoded metabolically stable analogue of phosphotyrosine in Escherichia coli.ACS Chem Biol 2007;2:474-478.

115. Liu CC, Schultz PG. Adding new chemistries to the genetic code. Annu Rev Biochem 2010;79:413-444.

116. Hoppmann C, Wong A, Yang B, et al. Site-specific incorporation of phosphotyrosine using an expanded genetic code. Nat Chem Biol 2017;13:842-844.

117. Wadhams GH, Armitage JP. Making sense of it all: bacterial chemotaxis. Nat Rev Mol Cell Biol 2004;5:1024-1037.

118. Lilley $M$, Synthesis and development of stable phosphohistidine analogues: The University of Sheffield, 2013. 